\title{
O maior erro de Einstein? Debatendo o papel dos erros na ciência através de um jogo didático sobre cosmologia ${ }^{+}$
}

\author{
Alexandre Bagdonas ${ }^{1}$ \\ Universidade Federal de Lavras \\ Lavras - MG \\ João Zanetic $^{2}$ \\ Ivã Gurgel $^{3}$ \\ Instituto de Física - Universidade de São Paulo \\ São Paulo - SP
}

\section{Resumo}

A constante cosmológica de Einstein, introduzida por ele como uma estratégia para manter seu modelo de universo estático, tem sido divulgada como um dos maiores erros de sua carreira. Em 1922, Einstein avaliou o artigo enviado por Friedmann para um periódico alemão, mostrando que existe uma solução das equações de campo da relatividade geral em que o tamanho do universo aumenta com o tempo. Einstein considerou que Friedmann teria cometido um erro nos cálculos, mas após discutir a questão com um colega de Friedmann, reconheceu seu engano, declarando que a proposta do universo em expansão seria matematicamente possível. Contudo, acreditava que essa ideia dificilmente teria algum sentido físico. Este episódio histórico foi adaptado para o contexto do ensino de Física do ensino médio através da criação de um jogo didático. Neste artigo, analisamos argumentos envolvendo a oposição entre Einstein e Friedmann e as concepções dos alunos sobre o papel dos erros na ciência. Houve um equilíbrio entre o número de alunos que apoiou Einstein ou Friedmann. Muitos dos fãs de Einstein tinham uma admiração ingênua, acreditando que alguém tão inteligente como ele não poderia cometer erros. Por outro lado, os fãs de Friedmann valorizaram sua atitude crítica, desafiando a autoridade de um cientista renomado.

\footnotetext{
+ Einstein's biggest blunder? Debating the role of errors in science through a didactic game about cosmology

* Recebido: outubro de 2017. Aceito: novembro de 2017.

${ }^{1}$ E-mail: alebagdonas@gmail.com; ${ }^{2}$ E-mail: zanetic@if.usp.br; ${ }^{3}$ E-mail: gurgel@usp.br
} 
Os alunos discutiram se o fato de que Einstein tenha admitido seu próprio erro deveria ou não ser valorizado. Com isso, notamos argumentos interessantes dos alunos sobre o papel dos erros na ciência, que motivaram a problematização do mito dos grandes gênios que nunca erram e cuja autoridade não deve ser questionada.

Palavras-chave: Erros; Cosmologia; Einstein; Friedmann; Natureza da Ciência; Autoridade.

\begin{abstract}
Einstein's cosmological constant, introduced by him as a strategy to keep his model of the universe as static, has been considered one of the biggest blunders throughout his career. In 1922, Einstein evaluated the paper submitted by Friedmann to a German journal, in which he showed that there is one solution to the general relativity field equations in which the size of the universe increases with time. Einstein initially considered Friedmann would have made mistakes during calculations, but after discussing this issue with one of Friedmann's colleagues, Einstein admitted he was wrong and accepted the expansion of the universe as a mathematical possibility. However, he believed it could hardly have any physical meaning. This historical episode was adapted to high school physics classes through the creation of a didactic game. In this paper, we analyze arguments about the opposition between Einstein and Friedmann and students conceptions about the role of errors in science. There was equilibrium between supporters of Einstein and Friedmann. Many of Einsteins fans had a naive admiration, believing that such a smart scientist could not make mistakes. On the other hand, Friedmann fans valued his critical attitude, challenging the authority of a famous scientist. Students debated whether the fact that Einstein admitted his mistake should be valued. Therefore we noted interesting students' arguments about the role of errors in science, which motivated the problematization of the myth of genius who never make mistakes and whose authority shall never be questioned.
\end{abstract}

Keywords: Errors; Cosmology; Einstein; Friedmann; Nature of science; Authority. 


\section{Introdução}

A cultura escolar vigente tem valorizado os acertos em detrimento dos erros. Professores costumam, desde as séries iniciais da educação infantil, parabenizar as respostas corretas e lamentar os equívocos, criando, em muitos casos, o medo dos alunos em expor suas ideias publicamente por receio de elas serem julgadas erradas. Costumam ser raras as oportunidades em que um erro é valorizado por sua oportunidade de aperfeiçoamento, como parte de um aprendizado mais profundo.

Por outro lado, educadores têm problematizado essa cultura escolar vigente, promovendo estratégias diversas para valorizar a participação dos alunos. Aulas que fomentam discussões respeitosas, debates e confronto organizado de opiniões, são formas reconhecidas de se fomentar a formação de cidadãos mais críticos em uma democracia participativa. Para que isso possa ocorrer com maior frequência, a ponto de estabelecer uma ruptura com a visão negativa normalmente associada aos erros nas escolas, a colaboração de educadores de diferentes formações é essencial.

Principalmente com o aumento da quantidade de informações disponíveis aos estudantes da educação básica, torna-se cada vez mais essencial a discussão sobre como a ciência é feita, como podemos evitar a propagação de informações erradas e como aproveitar os erros do passado como fonte de superação para nosso comportamento no futuro.

No caso particular do Ensino de Física, as aulas que exigem mera aplicação de fórmulas para a resolução de exercícios descontextualizados, com respostas certas e erradas já definidas previamente, não só deixam de contribuir para uma educação mais crítica, como tendem a reforçar posturas negativas sobre os erros nas ciências. Essa visão de educação fomenta nos estudantes comportamentos como a memorização, repetição acrítica de procedimentos e truques e a criação de relatórios de atividades experimentais em que os dados sempre corroboram as teorias (BORGES, 2002; CEDRAN et al. 2017).

Até mesmo a história da física encontrada nos livros didáticos mais tradicionais, que não incorporaram as críticas de pesquisadores interessados na contribuição da história e filosofia da ciência para o ensino de física, reforça uma visão negativa sobre o erro no ensino de ciências. Por exemplo, fortalece a visão ingênua de que os cientistas são gênios infalíveis, de que há um método científico a ser seguido pelos cientistas em direção à verdade, além de outros mitos que estão associados à visão de uma ciência neutra, algorítmica e dogmática, tão criticada por pesquisadores de ensino de ciências nas últimas décadas (GIL PÉREZ et al., 2001; MARTINS, 2006; PAGLIARINI, 2007; MARTINS, 2015, ACEVEDO-DÍAZ; GARCÍA-CARMONA, 2016).

Ao invés disso, professores de física, interessados em promover uma educação emancipadora, têm o desafio de fomentar o espírito crítico. Isso tem sido feito de diversas formas, como a partir de atividades investigativas, contextualizadas, que favorecem debates não só sobre diferentes teorias que podem explicar fenômenos naturais, mas principalmente sobre as complexas relações entre ciência, tecnologia e sociedade. 
Este tipo de atividade pode mostrar visões mais ricas e complexas sobre como a ciência é produzida, uma construção humana multifacetada repleta de erros e acertos. Para isso, é importante o estudo de episódios históricos que permitam a discussão mais profunda sobre aspectos do processo de construção e validação das teorias (ZANETIC, 1989; MATTHEWS, 1994; FORATO; GUERRA; BRAGA, 2014; CEDRAN et al., 2017). Muitos pesquisadores que defendem a atualização curricular pelo ensino da física moderna e contemporânea na educação básica, destacam a cosmologia como um assunto com grande potencial pedagógico, principalmente quando abordada com um enfoque histórico (AGUIAR, 2010; ARTHURY, 2010; AZEVEDO, 2011; BAGDONAS, 2011; SKOLIMOSKI, 2014; BAGDONAS, 2015).

Neste artigo analisamos discussões sobre o conceito de "erro" na ciência travadas entre alunos do primeiro ano do ensino médio de uma escola estadual paulistana durante um sequência de aulas com duração de 1 bimestre. Estas discussões foram fomentadas pelo estudo sobre história da cosmologia na primeira metade do século XX, em particular sobre a reação de Albert Einstein, que em 1922 já era um renomado cientista, à então inovadora proposta de Alexander Friedmann, de que o universo poderia estar em expansão.

\section{A reação de Einstein à teoria da expansão do universo}

Até a década de 1920, os estudos sobre a origem e estrutura do universo, o que hoje denominamos cosmologia, indicavam que este era composto por estrelas distantes num espaço estático e vazio. Nessa época estava se consolidando o conceito atual de galáxia, já que novas formas de medir distâncias de corpos astronômicos passavam a expandir cada vez mais os horizontes do universo conhecido (NORTH, 1965; KRAGH, 1996; BAGDONAS et al., 2009).

O chamado modelo cosmológico padrão, adotado pela maioria dos estudiosos em cosmologia, tem como premissa básica a hipótese de que a interação entre corpos do universo é de origem gravitacional. Atualmente, a teoria mais aceita para explicar essa interação, utilizada em quase todas as teorias cosmológicas, é a relatividade geral (WAGA, 2005; BAGDONAS, 2011, p. 69).

Com a criação da teoria da relatividade geral no fim da década de 1910, surgiram os primeiros modelos cosmológicos relativísticos, sendo o primeiro deles criado por Albert Einstein (1879-1955) em 1917. Ele explorou os resultados das equações de campo para o universo como um todo. Nessa época, o espaço era normalmente visto como estático. Porém a solução das equações de campo encontrada por Einstein era instável: todos os corpos teriam a tendência de se juntar em um ponto só, criando um colapso gravitacional do universo. Para resolver esse problema, Einstein introduziu em suas equações um fator chamado constante cosmológica, que representa um tipo de repulsão, equilibrando a atração gravitacional e permitindo a existência de um universo estático, em equilíbrio (EINSTEIN, 1917; SOARES, 2012). 
O cientista soviético Alexander Friedmann (1888-1925) começou a estudar a teoria da relatividade geral após 1920, quando a URSS voltou a receber artigos internacionais após um longo período de isolamento causado pela Revolução Russa e pela Guerra Civil (KOJEVNIKOV, 2004). Dois anos depois, publicou uma das primeiras grandes contribuições soviéticas à ciência: diversas soluções dinâmicas, ou seja, não estáticas, das equações da relatividade geral que não haviam sido encontradas nem por Einstein, nem por de Sitter em 1917 (FRIEDMANN, 1922).

Após apresentar as diversas soluções possíveis em um artigo predominantemente matemático ${ }^{2}$, Friedmann fez algumas sugestões cautelosas sobre como se poderia, no futuro, escolher entre os diversos modelos de universo.

Nosso conhecimento é insuficiente para realizar cálculos numéricos com a intenção de decidir qual é o nosso universo. É possível que os problemas da causalidade e da força centrífuga iluminem estas questões. Podemos notar que a quantidade cosmológica $\lambda$ permanece indeterminada nas nossas fórmulas, já que é uma constante arbitrária no problema. Talvez a eletrodinâmica ajude a defini-la. Se fizermos $\lambda=0$ e $M=5 \times 10^{21}$ massas solares, teremos um período do universo de 10 bilhões de anos. Estas visões certamente servem somente como ilustrações de nossos cálculos (FRIEDMANN, 1922, p.58, tradução nossa).

Einstein foi escolhido para ser o avaliador do artigo de Friedmann, submetido em 1922 à revista alemã Zeitschrift für Physik. Inicialmente, Einstein escreveu uma nota para a mesma revista considerando suspeitas as soluções com raio crescente, levando em conta que elas seriam incompatíveis com suas equações de campo. Um amigo de Friedmann, Yuri Krutkov (1890-1952), esteve em Berlim e contou a seu compatriota sobre a objeção de Einstein. Então, Friedmann revisou seus cálculos e escreveu uma carta para Einstein demonstrando que não havia erros em seu artigo:

Caro professor, a partir da carta de um amigo que agora está no exterior tive a honra de saber que você submeteu uma nota a ser impressa no $11^{\circ}$ volume da Zeitschrift für Physik, na qual afirma que se forem aceitas as suposições feitas em meu artigo "Sobre a curvatura do espaço", se concluirá, a partir das equações de campo derivadas por você, que o raio de curvatura do universo é uma quantidade independente do tempo (...) Se considerar os cálculos apresentados nesta carta corretos, por favor, tenha a gentileza de informar isso aos editores da Zeitschrift für Physik; talvez seja adequado você publicar uma correção de sua nota ou dar a oportunidade de que uma parte desta carta seja publicada (FRIEDMANN 1922 apud TROPP et al., 1993, p. 170, tradução nossa).

\footnotetext{
${ }^{2}$ Para mais detalhes sobre as soluções de Friedmann, ver VIGLIONI e SOARES (2011), BAGDONAS (2011, p. 75).
} 
Entre setembro de 1922 e março de 1923, Einstein estava viajando por diversos países (Suíça, França, Japão, Palestina e Espanha) e não leu a carta de Friedmann. Somente em maio de 1923, num evento em Leiden, que homenageava a aposentadoria do físico holandês H. Lorentz, Einstein encontrou-se com Yuri Krutkov (Ibidem, p.170). Eles discutiram sobre o suposto erro no artigo de 1922 e Krutkov, em uma carta para sua irmã, escreveu: "Eu ganhei de Einstein em um argumento sobre Friedmann. A honra de Petrogrado está salva" (Krutkov citado em FRENKEL, 2002, p. 7).

Logo em seguida Einstein publicou na Zeitschrift für Physik uma nova nota reconhecendo seu erro:

Em uma nota anterior (EINSTEIN, 1922) eu critiquei o artigo citado (FRIEDMANN, 1922). Minha objeção era baseada, no entanto, em um erro de cálculo, como me convenceram o Sr. Krutkov pessoalmente e o Sr. Friedmann em uma carta. Estou convencido de que os resultados do Sr. Friedmann são corretos e elucidativos. Eles mostram que além das soluções estáticas das equações de campo existem também soluções que variam no tempo com estrutura espacial simétrica (EINSTEIN, 1923, tradução nossa).

Em 1987, o historiador da ciência John Stachel encontrou um manuscrito de Einstein, idêntico ao trecho citado acima que foi publicado, porém com uma frase adicional, que deve ter sido apagada por Einstein na hora de enviar o artigo: "A solução de Friedmann de um universo não estático, ainda que correta matematicamente, dificilmente pode ter algum sentido físico" (STACHEL, 1987 apud FFRENKEL 2002, p.7, tradução nossa).

A partir da década de 1920, a maior parte dos interessados em cosmologia, como Friedmann, Lemaître e Eddington, adotaram a constante cosmológica de Einstein como uma possibilidade a ser investigada. Mesmo nos modelos de universo em expansão, a constante poderia ser não nula, alterando a velocidade de expansão do universo (KRAGH, 1996, p. 9, BAGDONAS, 2011, p. 74)

Em sua autobiografia, George Gamow (1904-1968) afirmou que durante seus encontros com Einstein, nos EUA, enquanto ambos trabalhavam com pesquisas militares durante a Segunda Guerra Mundial, o alemão teria dito que a constante cosmológica teria sido "o maior erro de sua carreira" (GAMOW, 1970). Porém, Gamow pode ter sido enfático demais na escolha das palavras. Não há documentação comprovando que Einstein realmente se arrependeu do uso desta constante, que continuou sendo empregada tanto por ele e por outros cosmólogos durante muito tempo (WEINSTEIN, 2013).

Essa visão anacrônica de Gamow, olhando para o passado com os olhos do presente e identificando a constante cosmológica como um erro grave, é comum na maior parte dos livros atuais sobre cosmologia relativística. Porém, na época, de fato era sensato assumir que o universo era estático.

A mudança de opinião de Einstein sobre teorias cosmológicas, aceitando que o universo em expansão era mais compatível com observações astronômicas, como o desvio 
espectral das galáxias, foi um processo complexo, que envolveu tanto aspectos empíricos, tais como o importante artigo de Hubble de 1929, quanto discussões teóricas sobre cosmologia travadas com o físico teórico Richard Tolman (1881-1948), um dos poucos especialistas em relatividade geral nos EUA nessa época (NUSSBAUMER, 2013). Einstein ainda propôs, em 1931, um modelo de universo do tipo Estado Estacionário, descoberto recentemente (RAIFEARTAIGH, 2014), mas a partir de 1932 parece ter se juntado a De Sitter, Eddington e Lemaître na defesa de que o universo está em expansão (EINSTEIN e DE SITTER, 1932).

Não deixa de ser curioso notarmos que atualmente a constante cosmológica voltou a ser considerada como uma das explicações para a energia escura, o que levou certos cosmólogos a proporem, cometendo um anacronismo extremo, que Einstein poderia ter previsto a energia escura ${ }^{3}$.

\section{Einstein e Friedmann em um jogo didático}

Este episódio histórico serviu de base para a criação de uma sequência de ensino e aprendizagem sobre história da cosmologia, que foi realizada por um grupo de pesquisa em ensino de física, composto por professores, tanto do ensino médio quanto de cursos de licenciatura. Os estudos de história da cosmologia foram debatidos nas reuniões semanais do grupo, guiando o processo de criação e aperfeiçoamento da sequência de ensino e aprendizagem entre abril de 2012 e junho de 2013 (BAGDONAS, 2015, p. 137).

A investigação da sequência de ensino e aprendizagem se deu em uma escola estadual paulistana, durante um bimestre. Seguindo as orientações dos Parâmetros Curriculares Nacionais e da Proposta Curricular do Estado de São Paulo, o estudo de Astronomia e Cosmologia aconteceu no segundo bimestre do primeiro ano do ensino médio.

Além de ensinar conceitos básicos de cosmologia, como universo estático e em expansão, desvio espectral para o vermelho e constante cosmológica, a sequência de ensino e aprendizagem tinha como objetivo central "permitir aos estudantes uma compreensão mais rica sobre as formas com que a ciência se relaciona com seu contexto histórico-social" (Ibidem, p. 141).

Para isso, foi criado um jogo didático, em que os personagens centrais são Einstein, Friedmann e outros cientistas que contribuíram para a criação e consolidação da teoria do universo em expansão entre 1914 e 1939. O jogo, que estrutura a sequência de ensino e aprendizagem, permite ao professor conduzir reflexões sobre possíveis relações entre a história política mundial e o desenvolvimento da cosmologia relativística (BAGDONAS, $2015)^{4}$.

\footnotetext{
${ }^{3}<$ http://hubblesite.org/hubble_discoveries/dark_energy/de-did_einstein_predict.php> é um exemplo deste tipo de anacronismo entre astrônomos, acesso em Setembro de 2017.

${ }^{4}$ Uma versão preliminar do jogo, durante seu processo de construção, foi apresentada e investigada em (GURGEL et al., 2013) e (BAGDONAS et al., 2014). Após concluída a intervenção didática, aspectos teóricos do
} 
Dessa forma, o estudo do episódio histórico e as discussões conceituais ocorridas ao longo do jogo didático visam fomentar também debates sobre a chamada natureza da ciência (BAGDONAS, 2013; MARTINS, 2015), tais como a influência de fatores subjetivos na interpretação das teorias, a possibilidade de desacordo entre cientistas que analisam os mesmos dados observacionais e o conceito de descoberta na ciência (BAGDONAS et al., 2017 a).

Buscamos, ao contrário do que têm defendido os adeptos da chamada "visão consensual da natureza da ciência", colocar em debate para os alunos um aspecto controverso: a tensão entre visões racionalistas e relativistas da ciência. Na seção IV, apresentamos as categorias de análise das concepções de ciência dos alunos, assim como os referenciais de história, filosofia e sociologia da ciência empregados para construí-las.

Nas duas primeiras atividades, houve uma introdução à cosmologia, caracterizando-a como o estudo do universo em larga escala, em oposição à astronomia, que trata do estudo mais detalhado dos componentes do universo (galáxias, estrelas, planetas e outros corpos celestes). Em seguida há uma apresentação do contexto histórico em que se dará o jogo didático.

O jogo tem uma estrutura que estimula o conhecimento do contexto histórico e geográfico da produção científica no início do século XX. Os alunos e professores interpretam papéis, como em um role playing game, atuando como membros de uma agência de fomento à pesquisa. Para isso, pesquisam informações sobre possíveis cientistas que têm desenvolvido pesquisas promissoras viajando para diferentes países. Ao longo das aulas, o tempo histórico no jogo vai passando, e novos acontecimentos históricos são conhecidos por meio da leitura sobre aspectos históricos, culturais e científicos em cada período ${ }^{6}$. O material do jogo consiste basicamente em fichas impressas em cartões plástico, que contêm fotos, desenhos e textos sobre acontecimentos históricos. Ele foi preparado pelo grupo de pesquisa TeHCo (Teoria e História do Conhecimento Científico e Escolar), a partir do estudo de fontes primárias e secundárias sobre a história da ciência na primeira metade do século $\mathrm{XX}^{7}$.

A tabela 1 apresenta as atividades da sequência de ensino de aprendizagem, que foram inspiradas nos Três Momentos Pedagógicos (DELIZOICOV; ANGOTTI; PERNAMBUCO, 2002), que foram reformulados para o contexto da proposta. Em cada fase do jogo há três momentos: a investigação, em que os alunos pesquisam as fichas de cada país com informações sobre cientistas ou países que podem receber financiamento; a organização, em

jogo, sem a análise dos dados empíricos coletados, foram apresentadas em (BAGDONAS et al., 2017 b; FORATO; BAGDONAS 2017).

${ }^{5}$ Para caracterizações e críticas desta postura, que defende, na educação básica, o ensino somente dos aspectos mais consensuais da natureza da ciência, ver (BAGDONAS et al., 2014; MARTINS, 2015 e BAGDONAS et al., 2017b).

${ }^{6}$ Para mais detalhes sobre as regras do jogo, ver (BAGDONAS, 2015, p.149; BAGDONAS et al., 2017 b).

${ }^{7} \mathrm{O}$ material do jogo está disponível em <http://lite.dex.ufla.br/pibidfisica/index.php/cosmic/>. A lista completa das fontes consultadas para a construção das fichas está em (BAGDONAS, 2015, p. 266). 
que o professor discute e aprofunda as questões mais importantes que emergiram a partir dos argumentos dos alunos, e a aplicação, em que se espera que os alunos empreguem o que foi aprendido nas etapas anteriores para formular um argumento mais bem embasado sobre que cientista merece receber financiamento na rodada.

Tabela 1: Visão global da estrutura do jogo $\operatorname{COSMIC}^{8}$.

\begin{tabular}{|c|c|c|}
\hline Investigação & Organização & Aplicação \\
\hline $\begin{array}{c}\text { Atividade } 3 \\
1^{\mathrm{a}} \text { fase } \\
(1914-1924)\end{array}$ & $\begin{array}{c}\text { Atividade } 4 \\
\text { Modelos estático e em expansão } \\
\text { Boicote sobre a ciência alemã }\end{array}$ & $\begin{array}{c}\text { Atividade } 5 \\
\text { Einstein x Friedmann }\end{array}$ \\
\hline $\begin{array}{l}\text { Atividade } 6 \\
2^{\mathrm{a}} \text { fase } \\
(1925-1931)\end{array}$ & $\begin{array}{c}\text { Atividades } 7 \text { e } 8 \\
\text { Relação redshift - distância, Efeito De } \\
\text { Sitter } \\
\text { Disputas de prioridade }\end{array}$ & $\begin{array}{c}\text { Atividade } 9 \\
\text { Lemaître x Hubble }\end{array}$ \\
\hline $\begin{array}{c}\text { Atividade } 11 \\
3^{\mathrm{a}} \text { fase } \\
(1932-1939)\end{array}$ & $\begin{array}{l}\text { Atividades } 11 \text { e } \mathbf{1 2} \\
\text { Teoria da luz cansada } \\
\text { Expansão do universo }\end{array}$ & $\begin{array}{c}\text { Atividade } 13 \\
\text { Avaliação geral }\end{array}$ \\
\hline
\end{tabular}

\section{Metodologia da pesquisa}

Neste artigo, detalhamos os argumentos que os alunos formularam ao longo das aulas, selecionando os que estavam relacionados às teorias cosmológicas de Einstein e Friedmann e aos debates envolvendo o papel dos erros na ciência. Esta discussão foi planejada como elemento central na $1^{\text {a }}$ fase do jogo, que corresponde ao período de 1914 a 1924. Por isso, empregamos principalmente os dados de pesquisa coletados durante as atividades 3,4 e 5 .

A investigação da sequência de ensino e aprendizagem aconteceu entre abril e junho de 2013, em três turmas do primeiro ano do ensino médio da E.E. Ana Rosa, escola estadual situada na zona oeste de São Paulo. Muitos dos alunos moram em regiões mais afastadas e têm que viajar grandes distâncias até chegar à escola. As classes tinham cerca de 40 alunos matriculados e a infraestrutura da escola era similar a outras escolas da região, incluindo laboratório de informática, quadra de esportes coberta, TV e projetor multimídia. Este último foi utilizado em diversas aulas para apresentar slides.

Durante toda a sequência investigamos as concepções dos alunos sobre a ciência, problematizando visões ingênuas e inserindo gradativamente elementos controversos em complexidade crescente ao longo das atividades. Em diversas atividades dados de pesquisa foram coletados para avaliar a evolução das visões dos alunos sobre a ciência ao longo das

\footnotetext{
${ }^{8}$ Inicialmente não empregamos os Três Momentos Pedagógicos como referencial teórico para a construção da sequência. Percebemos posteriormente que as leituras feitas pelo grupo sobre a pedagogia freireana acabaram influenciando a criação do jogo.
} 
aulas. A metodologia de pesquisa utilizada foi a abordagem qualitativa (BOGDAN; BIKLEN, 1994), comum em pesquisas de educação.

Houve questões respondidas na classe, oralmente ou por escrito, e no blog da disciplina, além dos argumentos formulados durante o jogo, primeiro expostos oralmente, e posteriormente registados por escrito. Além disso, houve também anotações feitas pelo professor da escola e pelo primeiro autor deste artigo, nas conversas entre eles nos intervalos das aulas. Assim pudemos realizar a triangulação, comparando fontes de dados distintas (CARVALHO, 2006).

Em todas as transcrições apresentadas a seguir adotamos pseudônimos para os alunos. Nas transcrições de vídeo, indicamos a cor que identifica o grupo (AMARELO, AZUL, MARROM, VERMELHO ou LARANJA) ou aluno que enunciou a fala, sua classe ( $1^{\circ}$ $\mathrm{A}, 1^{\circ} \mathrm{B}$ ou $1^{\circ} \mathrm{C}$ ), o tempo contado no arquivo de cada gravação (Minutos: Segundos), e o número da aula. (Ex: Amarelo C, 41:30, Aula 3).

\section{Categorias empregadas para a análise dos dados}

Para analisar as concepções de ciência dos alunos ao longo das aulas, empregamos três categorias, que foram inspiradas principalmente na tensão entra as visões epistemológicas dos filósofos Imre Lakatos (1922-1974) e Paul Feyerabend (1924-1994). Ambos estudaram na década de 1950 em Londres, onde foram orientados em seus estudos por Karl Popper (19021994), que lecionava na London School of Economics.

Posteriormente, Feyerabend ficaria conhecido como um dos mais famosos defensores do relativismo, distanciando-se radicalmente da visão racionalista de Popper. Seu livro mais famoso, Contra o Método (1975), mostra sua visão crítica tanto da obra de Popper, quanto do racionalismo crítico de Lakatos. Sua postura epistemológica ficou conhecida como "anarquismo epistemológico" ou "pluralismo metodológico" (BAGDONAS, 2015, p. 56).

As três categorias empregadas foram Racionalismo, Relativismo e Posturas moderadas.

\section{Racionalismo}

Esta categoria é inspirada principalmente na epistemologia de Lakatos e sua defesa de que a história externalista da ciência tem um papel secundário quando comparado com a reconstrução racional da história interna da ciência (LAKATOS, 1971, p.41; BAGDONAS, 2015, p.62). Os adeptos dessa visão dão mais atenção aos conteúdos cognitivos da ciência, com pouca atenção ao contexto sociocultural. Também são compatíveis com esta categoria os valores do ethos científico, apresentados pelo sociólogo estadunidense Robert Merton (19102003): universalismo, comunalidade, desinteresse e ceticismo organizado (MERTON, 2013; BAGDONAS, 2015, p.59). Uma versão ingênua dessa visão foi denominada racionalismo cientificista por Marco Barbosa de Oliveira, em seus estudos sobre a epistemologia de Hugh Lacey. Nessa visão, a ciência seria neutra, mas a sociedade pode usá-la para o bem ou para o 
mal (OLIVEIRA, 2003). Outra visão ingênua da natureza da ciência que se enquadra nesta categoria foi denominada empírico-indutivista ou absolutista, por pesquisadores que adotaram visão consensual da natureza da ciência (GIL PÉREZ et al., 2001).

\section{Relativismo}

Esta categoria é inspirada principalmente no anarquismo epistemológico de Paul Feyerabend e por autores que criticaram a autoridade científica, como certos adeptos do Programa Forte da Sociologia das Ciências. Classificamos nela os alunos que enfatizaram aspectos sociais da ciência, dando mais atenção ao contexto sócio-histórico que aos conteúdos; ou que questionaram a autoridade da ciência e os valores do ethos científico, enfatizando aspectos não racionais das condutas dos cientistas, como orgulho intelectual, disputas por poder e prestígio, adesão dogmática ao paradigma vigente, entre outras.

Marco Barbosa de Oliveira (2003) caracterizou como relativista a corrente pósmoderna de crítica à ciência, que argumenta que a ciência não é nem neutra nem imparcial. No entanto, é importante ressaltar que há importantes divergências entre autores pósmodernos, autores do Science Studies, muitos dos quais não se dizem relativistas. Essa categorização dicotômica entre "Relativismo" e "Racionalismo" foi empregada para analisar as concepções de estudantes do ensino médio, mas é certamente muito simplificada em relação às concepções de profissionais dedicados a estudos sobre história, filosofia e sociologia da ciência.

\section{Posturas moderadas}

Vários filósofos da ciência propuseram teorias epistemológicas moderadas, evitando extremos do positivismo e do relativismo: Gaston Bachelard, Thomas Kuhn, Stephen Toulmin, Larry Laudan, Fourez (1995) e Oliveira (2003). No âmbito da pesquisa em ensino de ciências, estes autores influenciaram fortemente a consolidação da chamada "visão consensual da natureza da ciência" (BAGDONAS et al., 2014).

Para nossa análise, classificamos como moderadas as visões de ciência que tendiam a um equilíbrio entre internalismo e externalismo, conteúdo e contexto, e que defenderam os valores do ethos científico, porém reconhecendo que eventualmente os cientistas podem agir em desacordo com estes valores.

\section{Argumentos dos alunos do ensino médio sobre erros na ciência}

Seguindo a dinâmica do jogo, na atividade 3, após pesquisar nas fichas, os alunos deveriam escolher um país para receber financiamento. Na atividade 4 houve discussões sobre os argumentos dos alunos e alguns modelos cosmológicos, em particular o universo Estático de Einstein e o universo em expansão de Friedmann foram discutidos em detalhe. Finalmente 
na atividade 5 os alunos voltaram a formular um argumento, agora sobre qual cientista deveria receber financiamento.

$\mathrm{Na}$ atividade 3, como esperado, houve poucos argumentos com alguma apropriação de conteúdos. Dos 22 argumentos categorizados, 7 tinham relação mais próxima com conteúdos de cosmologia, enquanto 15 estavam mais relacionados com o contexto sóciohistórico: questões militares, econômicas, religiosas ou sobre a participação das mulheres na ciência (BAGDONAS, 2015, p.227). Eis um exemplo de voto de um grupo nessa atividade 3:

Voto: Rússia. Cartão: "Einstein rejeita solução de Friedmann". Baseando-se no sucesso de Friedmann em se defender das críticas de Einstein ao modelo de universo em expansão, este grupo escolheu a URSS porque "tinha um conhecimento científico a ponto de se defender das teorias de Einstein" (Grupo Preto B, Aula 3 36:00).

Einstein e Friedmann não foram mencionados em nenhum argumento de qualquer outro grupo na atividade 3. Após a aula 4, em que os conteúdos de cosmologia foram introduzidos pelo professor, os alunos conseguiram criar argumentos mais pautados em aspectos científicos na atividade 5. Dos 33 argumentos categorizados, 15 envolviam conteúdos de cosmologia e 18, aspectos sócio-históricos (BAGDONAS, 2015, p. 168). Houve praticamente um empate na disputa entre os que apoiaram o universo estático de Einstein e De Sitter (7 grupos) e o universo em expansão de Friedmann (5 grupos).

O debate entre Einstein e Friedmann sobre a expansão do universo dividiu os alunos em todas as classes ${ }^{9}$. Um dos defensores de Einstein o valorizou por ter se tornado famoso: "logo deve ter tido argumentos melhores que Friedmann" (Laranja B). Ainda que seja um argumento de autoridade, é baseado no reconhecimento da competência dos cientistas em decidir quais foram as melhores teorias.

Einstein também foi valorizado por reconhecer que sua postura sobre o modelo de Friedmann estava inicialmente equivocada. Além de ser uma virtude ética, isso teria ajudado Einstein a aprimorar suas próprias teorias cosmológicas. Este ponto gerou um debate intenso, já que um dos defensores de Friedmann discordou:

Marrom: Ele [Einstein] reconheceu o erro, mas e dai? Que isso ajuda na cosmologia? Não é querendo ser arrogante, mas ele é esperto. Reconhecer erro não ajuda em nada a pesquisa

Vermelho: É importante reconhecer um erro porque isso ajuda ele a entender melhor sua própria teoria. Alguém de fora ajudou ele a ver erros que sozinho não conseguiu.

Marrom: tudo bem, é bacana reconhecer, mas isso não é um argumento que justifique dar prêmio pra ele. (Atividade 5, 1C, 33')

\footnotetext{
${ }^{9} \mathrm{O}$ resumo e categorização dos principais argumentos da atividade 5 pode ser consultado em BAGDONAS, 2015, p. 167. Já o detalhamento de todos os argumentos encontra-se na página 239.
} 
Já Friedmann, foi valorizado por questionar cientistas renomados, como Einstein, e mostrar que cientistas comuns podem duvidar sobre o que normalmente acredita a maior parte deles. Trata-se da valorização do que Merton denominou "ceticismo organizado".

Nas três salas, os valores defendidos pelos grupos vencedores eram algumas das normas éticas da ciência estudadas por Robert Merton (2013): originalidade, coragem de desafiar a autoridade, humildade, autocrítica e reconhecimento dos próprios erros. Vemos assim que mesmo com uma abordagem da história, filosofia e sociologia da ciência, a maioria dos alunos manteve sua defesa da ciência, posicionando-se mais próximos ao racionalismo do que ao relativismo.

Muitos dos que defenderam o universo estático foram influenciados pela fama de Einstein como um cientista excepcional. Eles demonstraram uma compreensível, mas ingênua, admiração pelo cientista que foi escolhido pela revista Time como a personalidade mais influente no século XX. Isso os levou a considerar que Friedmann deveria estar errado nessa disputa, simplesmente por que "Einstein era um dos melhores físicos da época, pelo fato dele não aceitar muito provavelmente tinha uma explicação muito boa” (Zazá A).

A questão 3 do $\operatorname{blog}^{10}$ convidava os alunos a avaliarem se:

A) Einstein teve uma conduta científica adequada ao rejeitar o modelo de Friedmann, pois não havia nenhum experimento comprovando que ele fosse verdadeiro.

B) Einstein foi influenciado pela visão de mundo de sua época, sendo compreensível que ele evitasse aceitar a ideia do universo em expansão facilmente.

C) $O$ caso de Einstein não foi uma exceção, pois cientistas famosos sempre relutam em aceitar novidades que contrariem as suas próprias teorias.

Vários alunos demonstraram a crença de que grandes "gênios" excepcionais, como Einstein, não podem ser questionados e ninguém deve duvidar deles. Além disso, Einstein teria feito tudo sozinho, sem a contribuição de nenhum outro cientista.

A) Discordo. Pois Einstein era muito inteligente e ninguém duvidava dele

B) Discordo. Ele nunca precisou de ajuda nenhuma para ser quem ele é

C) Concordo. Cada cientista tem sua teoria, seu modo de falar, seu jeito, seu modo de trabalho. (Lalá)

Mesmo com a problematização do empírico-indutivismo, é compreensível que estas concepções sejam difíceis de se alterar. A análise da questão 3 respondida no blog, após a atividade 4, nos mostrou que essas visões ingênuas sobre a ciência continuaram presentes, o que confirma o resultado de inúmeras pesquisas sobre concepções de natureza da ciência de estudantes do ensino médio (BAGDONAS, 2015, p.31) ${ }^{11}$.

\footnotetext{
${ }^{10}$ Ver detalhamento das respostas a essa questão em BAGDONAS, 2015, p. 233.

${ }^{11}$ Para uma revisão da literatura sobre pesquisas de concepções sobre natureza da ciência, ver Hodson 2014.
} 
A análise das escolhas dos alunos, realizadas ao longo do jogo didático, permitiu o reconhecimento de visões complexas sobre a natureza da ciência, em que parecem coexistir visões distintas. Uma das questões mais interessantes foi a possibilidade de notarmos diferenças entre visões prescritivas e descritivas da ciência. Alguns alunos que se engajaram no jogo aceitaram que existem influências teóricas no modo como cientistas interpretam as observações científicas, tendendo a uma visão mais próxima ao construtivismo social quando falam da ciência real, sua visão descritiva. Porém, mantiveram, como no início, uma defesa prescritiva de valores típicos do ethos científico.

O aluno Jajá concordou com a afirmação A, e discordou da afirmação B. Suas justificativas mostram que sua visão é próxima ao "racionalismo" / "empirismo", enfatizando a comprovação experimental para avaliar como adequada a mudança de visão de Einstein em relação à expansão do universo:

A) Concordo. Mesmo não tendo aceito que sua teoria está errada inicialmente, após ter tido comprovada a hipótese, ele se retrata e assume que está errado, na minha opinião ele agiu certo.

B) Discordo. Einstein não se influenciara pelas teorias da época tanto que ele mesmo provou que muitas delas estavam erradas.

Se ele respondesse a um questionário sobre natureza da ciência, sua visão seria provavelmente classificada como ingênua: empírico-indutivista, já que fala em provar teorias e dá a noção de que o cientista é neutro e individualista, sem se influenciar pelas teorias de sua época ${ }^{12}$.

Porém, notamos que ele também concordou com a alternativa $\mathrm{C}$, mostrando uma tensão entre uma visão racionalista, de como a ciência deveria ser e uma visão diferente de como, na prática, cientistas nem sempre agem de modo totalmente racional:

C) Concordo. Creio que todo cientista defenderá suas teorias, porém todos deixam espaço para o desconhecido e geralmente aceitam quando suas teorias estão erradas. (Jajá 1C)

Outros alunos, como Jajá, também valorizaram a atitude de Einstein ao admitir que estava errado, após ter debatido o modelo de Friedmann com Kruktov.

C) Discordo. Um cientista sempre tenta provar que está correto, sempre estuda procurar respostas claras para as suas pesquisas, Einstein admitiu que estava errado. Um cientista sempre quer ter a razão, cientista sempre tenta provar que está correto (Cacá 1C).

\footnotetext{
${ }^{12}$ Um exemplo de questionário muito utilizado em pesquisas sobre concepções de natureza da ciência é o VNOS, criado por Lederman e colaboradores (2002), traduzido para o português e utilizado no Brasil por Teixeira e colaboradores (2009).
} 
A aluna Lili defendeu que a postura de Einstein foi inadequada, porque cientistas devem se manter sempre abertos a novas possibilidades, analisando-as racionalmente.

A) Discordo. Mesmo que tal modelo não pudesse ser comprovado como verdadeiro ainda, Einstein deveria levar em conta que se poderia analisar a possibilidade de ter alguma lógica.

B) Concordo. Sim, porque baseado nos conhecimentos da época ele foi influenciado a evitar aceitar a ideia do universo em expansão, e por um provável orgulho que também o influenciou.

C) Concordo, porque apesar da ciência em si ser o ponto principal, os cientistas, talvez por um certo orgulho, quisessem sempre estar certos, assim relutando até que a teoria reversa a sua seja comprovada. No plano pratico da ciência como os fatos são, ou seja, muitas vezes os cientistas por orgulho relutam em aceitar algo que os contrarie ou teorias que contrariem as suas. (Lili A, grifo nosso).

Outra postura bem interessante, mostrando tensões entre os valores da comunidade científica e a prática real dos cientistas, foi a do aluno Gagá, que defendeu que é até saudável que a comunidade científica mostre certa resistência às ideias inovadoras.

A) Discordo. Porque todo artigo, dentre eles conceitos de novas teorias, tinham que ser avaliados por uma pessoa que entendesse do assunto, e o artigo de Friedmann foi para uma avaliação na Alemanha, e a única pessoa que tinha condições para avaliá-lo era o Einstein. Mas o artigo tinha conceitos contrários aos de Einstein, pois sendo o parecerista do artigo, teve como resposta que Friedmann tinha errado e sua teoria era suspeita. Porém falou isso concluindo a teoria de Friedmann como "errada" para defender seu ponto de vista científico não declarando que a teoria de Friedmann estava certa e assumindo que tinha errado.

B) Concordo. Porque a maioria dos cientistas quando tinham pontos de vista estranhos para eles não aceitavam logo de "cara", analisavam a teoria e comparavam com as suas para ter uma conclusão.

C) Concordo. Porque, eles sempre vão resistir a novos pontos de vista, por terem suas próprias teorias, tendo um ponto de vista contrário não vão aceitar, vão analisar até chegar a uma conclusão que prove que ele está errado, um ex: seria sobre Newton e Einstein, quando Einstein teve um ponto de vista contrário ao de Newton e, os ingleses não aceitaram e colocaram Eddington para analisar a teoria de Einstein e provar que ele estava errado e para provar que a ciência inglesa era melhor do que qualquer outra. Porque todo cientista que tem sua teoria mesmo com um que esteja ao contrário, ele vai ter um senso crítico de avaliar, analisar, julgar para ver se o seu ponto de vista estará correto ou não, ou seja, cheguei à conclusão de que todo cientista que tiver uma teoria vai aplicar e defendê-la. (Gagá A, grifo nosso). 
Uma postura semelhante, que valoriza uma espécie de dogmatismo por parte dos cientistas, foi defendida por Thomas Kuhn (1963). Lakatos (1971), ao contrário de Feyerabend, também defendia que é sensato que as agências de fomento neguem verba e aceitem propostas inovadoras, a menos que elas se mostrem promissoras a longo prazo.

Lili e Gagá discordaram de A, concordando com B e C, aproximando-se de posturas moderadas, entre o racionalismo e o relativismo, ao falar de sua visão descritiva de ciência. Entretanto, notamos que eles mantiveram sua defesa prescritiva da neutralidade da ciência, ou de valores típicos do ethos científico, como o senso crítico ao analisar teorias de modo racional.

Parece-nos razoável supor que os alunos mais engajados no jogo aprenderam mais sobre como podem se dar influências sociais sobre a ciência, o que os fez se distanciarem do empírico-indutivismo ingênuo. Assim, ao contrário dos alunos que ingenuamente argumentaram que Einstein teria sido um grande gênio, seria infalível, estes alunos têm uma confiança mais madura e sofisticada sobre a ciência, vendo erros como parte natural do processo de criação e validação das teorias.

\section{Considerações finais}

Autores como Gaston Bachelard (1996), ao propor a ciência como um conhecimento retificado, consideram que o erro é uma etapa fundamental para o desenvolvimento científico. Contudo, em uma análise mais detalhada podemos notar que a maneira como um erro é considerado pode refletir maneiras muito distintas de se pensar a natureza da ciência. Em um extremo de um espectro, o erro pode ser considerado um desvio de uma postura considerada adequada para o fazer científico. Nesta perspectiva, sua correção significa "recolocar a ciência nos trilhos", garantido o ethos científico. Em outro extremo, podemos considerar a ciência uma prática complexa na qual erros e acertos ocorrem concomitantemente, sendo assim o erro inerente às ciências. A primeira postura pode ser aproximada a uma postura racionalista da ciência, enquanto a segunda, a uma postura relativista.

As reflexões de alunos do ensino médio motivados por estudos de história da cosmologia durante um jogo didático nos permitiram reconhecer e problematizar visões ingênuas da ciência, tais como a visão empírico-indutivista e o mito dos gênios que nunca erram. Este resultado corrobora o que tem sido apontado pela grande maioria dos pesquisadores interessados no uso da história e filosofia da ciência para ensinar conteúdos científicos e sobre a natureza da ciência na educação básica. Nas falas dos estudantes as posturas racionalistas e relativistas se manifestaram em um debate intenso em torno da autoridade científica de Einstein, em alguns momentos se valorizando o fato dele ter admitido a má avaliação do artigo de Friedmann, em outros se tomando este acontecimento como uma denúncia contra a ciência.

Além disso, o debate sobre questões controversas da natureza da ciência, em particular sobre o papel de fatores como política, economia e religião na criação de teorias 
cosmológicas, permitiu o reconhecimento de nuances interessantes nas visões dos alunos. Foi particularmente interessante notar diferenças significativas entre visões descritivas e prescritivas da ciência, já que alunos mostraram ser possível a convivência de visões mais racionalistas sobre como a ciência deveria ser, com visões mais relativistas sobre como a ciência é, de fato, ou costuma ser.

Como implicações para pesquisas futuras sobre concepções de ciência, mostra-se importante confrontar as respostas dadas pelos sujeitos de pesquisa a questionários consagrados como o VNOS, com entrevistas que permitam diferenciar nuances como as visões prescritivas e descritivas.

\section{Agradecimentos}

A todos os membros do grupo TeHCo (Teoria e História do Conhecimento) que desenvolveram a sequência de ensino aprendizagem investigada e aos alunos que contribuíram com a pesquisa. A pesquisa recebeu financiamento da FAPESP, processo 11/07728-4.

\section{Referências bibliográficas}

ACEVEDO-DÍAZ, J. A.; GARCÍA-CARMONA, A. Algo antiguo, algo nuevo, algo prestado. Tendencias sobre la naturaleza de la ciencia en la educación científica. Revista Eureka sobre Enseñanza y Divulgación de las Ciencias, v. 13, n. 1, 2016.

AGUIAR, R. R. Tópicos de Astrofísica e Cosmologia: uma aplicação de Física Moderna e Contemporânea no Ensino Médio. 2010. Dissertação (Mestrado em Ensino de Física) Programa Interunidades em Ensino de Ciências, Universidade de São Paulo, São Paulo.

ARTHURY, L. H. M. A cosmologia moderna à luz dos elementos da epistemologia de Lakatos. 2010. Dissertação (Mestrado em Ensino de Física) - Curso de Pós-graduação em Educação Científica e Tecnológica, UFSC, Florianópolis.

AZEVEDO, H. Competência comunicativa de futuros professores frente à diversidade religiosa na abordagem do Tema "origens do universo". 2011. Dissertação (Mestrado em Ensino de Física) - Faculdade de Ciências. Universidade Estadual Paulista.

BAGDONAS, A.; ANDRADE, V. F.; SILVA, C. C. Discutindo a natureza da ciência a partir de episódios da história da cosmologia: O Grande Debate. In: SIMPÓSIO NACIONAL DE ENSINO DE FÍSICA, XVIII, 2009, Vitória, ES. Atas...

BAGDONAS, A. Discutindo a natureza da ciência a partir de episódios da história da cosmologia. 2011. Dissertação (Mestrado em Ensino de Física) - Programa Interunidades em Ensino de Ciências, Universidade de São Paulo, São Paulo.

BAGDONAS, A.; ZANETIC, J.; GURGEL, I. Controvérsias sobre a natureza da ciência como enfoque curricular para o ensino de física: o ensino de história da cosmologia por meio de um jogo didático. Revista Brasileira de História da Ciência, v. 7, n. 2, p. 242-260, 2014. 
BAGDONAS, A. Controvérsias envolvendo a natureza da ciência em sequências didáticas sobre cosmologia. 2015. Tese (Doutorado em Ensino de Física) - Programa Interunidades em Ensino de Ciências, Universidade de São Paulo, São Paulo.

BAGDONAS, A.; ZANETIC, J.; GURGEL, I. Quem descobriu a expansão do universo? Disputas de prioridade como forma de ensinar cosmologia com uso da história e filosofia da ciência. Revista Brasileiro de Ensino de Física, v. 39, p. 2602, 2017 a.

BAGDONAS, A.; FABRÍCIO, V.; GURGEL, I.; NORONHA, A; VELASQUEZ, F. A didactic game about cosmology designed to tackle controversies about science. In: PIETROCOLA, M.; GURGEL, I. (Org.). Crossing the Border of Traditional Science Curriculum: innovative teaching and learning in Science Basic Education. 1. ed. Boston: Sense Publishers, 2017 b. p. $163-179$.

BACHELARD, G. A Formação do Espírito Científico. São Paulo: Contraponto, 1996.

BOGDAN, R. C.; BIKLEN, S. Investigação qualitativa em educação uma introdução à teoria e aos métodos. Tradução: ALVAREZ, M. J.; SANTOS, S. B.; BAPTISTA, T. M. Porto Editora, 1994. 336 p.

BORGES, A. T. Novos rumos para o laboratório escolar de ciências. Caderno Brasileiro de Ensino de Física, v. 19, n. 3, p. 291-313, 2002.

CARVALHO, A. M. P. Uma metodologia de pesquisa para estudar os processos de ensino e aprendizagem em salas de aula. In: SANTOS, F. T.; GRECA, I. (Org.) A Pesquisa em Ensino de Ciências no Brasil e suas Metodologias. Ijuí: Editora Unijuí, 2006

CEDRAN, D. P.; LINO, A.; NEVES, M. C. D.; KIOURANIS, N. M. M. A natureza da Ciência e o erro: reflexões sobre o conto "Ótima é a Água" por alunos de Ensino Médio. Góndola, Enseñanza y Aprendizaje de las Ciencias, v. 12, n. 1, p. 43-56, 2017.

Delizoicov, D.; ANGOTTI, J. A.; PERnAMBuCO, M. M. Ensino de Ciências: fundamentos e métodos. São Paulo: Cortez Editora, 2002. 368 p.

EINSTEIN, A. Kosmologische Betrachtungen zur Allgemeinen Relativit"atstheorie, Sitzungsberichte der Koniglich Preußischen Akademie der Wissenschaften (Berlin), v. 142. Seite 142-152, 1917. Tradução para o inglês: Cosmological considerations on the general theory of the relativity, In: BERNSTEIN, J.; FEINBERG, G. Cosmological constants: papers in modern cosmology. New York: Columbia University Press, 1986. p. 1627.

EINSTEIN, A. Bemerkung zu der Arbeit von A. Friedmann Uber die Krummung des Raumes, Zeitschrift für Physik, v. 11, p. 326, 1922. 
EINSTEIN, A. Bemerkung zu der Arbeit von A. Friedmann Uber die Krummung des Raumes. Zeitschrift für Physik, v. 16, p. 228, 1923. Tradução para o inglês: Comments on the work of A Friedmann. In: BERNSTEIN, J.; FEINBERG, G. Cosmological constants: papers in modern cosmology. New York: Columbia University Press, 1986. p. 66-68.

EINSTEIN, A.; DE SITTER, W. On the relation between the expansion and the mean density of the Universe. Proceedings of the National Academy of Sciences of the United States of America, v. 18, n. 3, p. 213, 1932.

FEYERABEND, P. K. Against method: outline of an anarchistic theory of knowledge. Atlantic Highlands, NJ: Humanities Press, 1975. Tradução para o português: Contra o método. Editora UNESP, 2007.

FORATO, T.; GUERRA, A.; BRAGA, M. Historiadores das ciências e educadores: frutíferas parcerias para um ensino de ciências reflexivo e crítico. Revista Brasileira de História da Ciência, v. 7, n. 21, p. 137-141, 2014.

FORATO, T.; BAGDONAS, A. Overcoming obstacles for the use of history of science to teach science and nature of science. In: PIETROCOLA, M; GURGEL, I. (Org.). Crossing the border of Traditional Science Curriculum: innovative teaching and learning in Science Basic Education. 1. ed. Boston: Sense Publishers, 2017. p. 181-206.

FOUREZ, G. A construção das ciências: introdução à filosofia e à ética das ciências. São Paulo: Editora da UNESP, 1995. 320p.

FRENKEL, V. Einstein and Friedmann. In: BALASHOV, Y.; VIZGIN, V. P. Einstein Studies in Russia, Birkhäuser, 2002.

FRIEDMANN, A. Über die krümmung des raumes, Zeitschrift für Physik, v. 10, p. 377386, 1922. Tradução para o inglês: BERNSTEIN, J.; FEINBERG, G. On the curvature of space. In: Cosmological constants: papers in modern cosmology. New York: Columbia University Press, 1986. p. 49-59.

GURGEL, I.; BAGDONAS, A.; VELASQUEZ, F.; FABRÍCIO, V.; NORONHA, A. O Ensino sobre a Natureza da Ciência através de Tópicos de Cosmologia: Análise de uma Proposta Didática Utilizando Jogos. In: ENCONTRO NACIONAL DE PESQUISA EM EDUCAÇÃO EM CIÊNCIAS, IX, 2013, Águas de Lindoia. Atas...

HODSON, D. Nature of Science in the Science Curriculum: Origin, Development, Implications and Shifting Emphases. In: MATTHEWS, M. R. (Ed.). International Handbook of Research in History, Philosophy and Science Teaching. Springer Netherlands, 2014. p. 911-970. 
GAMOW, G. My world line: An informal autobiography. New York: Viking Press, 1970. $193 \mathrm{p}$.

GIL-PÉREZ, D.; MONTORO, I. F.; ALÍS, J. C.; CACHAPUZ, A.; PRAIA, J. Para uma Imagem Não-deformada do Trabalho Científico. Ciência \& Educação, v. 7, n. 2, p.125-153, 2001.

KOJEVNIKOV, A. Stalin's great science: the times and adventures of Soviet physicists. London: Imperial College Press, 2004. 360 p.

KUHN, T. The Function of Dogma in Scientific Research. In: CROMBIE, A. C. (Ed.). Scientific Change (Symposium on the History of Science, University of Oxford, 9-15 July 1961). New York and London: Basic Books and Heineman, 1963, p. 347-369.

KRAGH, H. Cosmology and Controversy: The Historical Development of Two Theories of the Universe. Princeton: Princeton University Press, 1996. 500p.

LAKATOS, I. History of science and its rational reconstructions. Springer Netherlands, 1971. Tradução para o português: História da ciência e suas reconstruções racionais. Lisboa: Edições 70, 1978. 176 p.

LEDERMAN, N. G.; ABD-EL-KHALICK, F; BELL, R. L.; SCHWARTZ, R. S. Views of nature of science questionnaire: Toward valid and meaningful assessment of learners' conceptions of nature of science. Journal of research in science teaching, v. 39, n. 6, p. 497 $521,2002$.

MARTINS, R. A. Introdução: a história das ciências e seus usos na educação. In: SILVA, C. C. (Org.) Estudos de história e filosofia das ciências: subsídios para aplicação no ensino. São Paulo: Editora Livraria da Física, 2006. cap.1. p.17-30.

MARTINS, A. F. P. Natureza da Ciência no ensino de ciências: uma proposta baseada em "temas" e "questões". Caderno Brasileiro de Ensino de Física , v. 32, n. 3, p. 703-737, 2015.

MATTHEWS, M. R. Science teaching: the role of history and philosophy of science. New York: Routledge, 1994. 287 p.

MERTON, R. K. Ensaios de sociologia da ciência. Tradução: Sílvia G. Garcia; Pablo Mariconda. Organização: Anne Marcovitch; Terry Shin. São Paulo: Editora 34, 2013. 304 p.

NORTH, J. D. Measure of the universe: a history of modern cosmology. New York: Dover, (edição de 1991), 1965.436p.

NUSSBAUMER, H. Einstein's conversion from his static to an expanding universe. European Physical Journal H, DOI 10.1140/epjh/e2013-40037-6. 
OLIVEIRA, M. B. Considerações sobre a neutralidade da ciência. Trans/Form/Ação, v. 26, n. 1, 2003.

PAGLIARINI, C. R. Uma análise da história e filosofia da ciência presente em livros didáticos de física para o ensino médio. 2007. Dissertação (Mestrado em Física Básica) Instituto de Física de São Carlos, Universidade de São Paulo, São Carlos.

RAIFEARTAIGH, C. Einstein's steady-state cosmology. Physics World, v. 27, n. 9, p. 30, 2014.

SKOLIMOSKI, K. Cosmologia na teoria e na prática: possibilidades e limitações no ensino. 2014. Dissertação (Mestrado em Ensino de Física) - Programa Interunidades em Ensino de Ciências, Universidade de São Paulo, São Paulo.

SOARES, D. O universo estático de Einstein. Revista Brasileira de Ensino de Física, v. 34, n. 1, 1302, 2012.

TEIXEIRA, E. S.; FREIRE JÚNIOR, O.; EL-HANI, C. N. A influência de uma abordagem contextual sobre as concepções acerca da natureza da ciência de estudantes de Física. Ciência \& Educação, v. 15, p. 529-556, 2009.

TROPP, E. A.; FRENKEL, Y. A.; CHERnIN, A. D. Alexander A. Friedmann: The man who made the universe expand. Cambridge: Cambridge University Press, 1993. 280p.

VIGLIONI, A.; SOARES, D. Observações sobre as soluções clássicas da equação de Friedmann. Revista Brasileira de Ensino de Física, v. 33, n. 4, 2011.

WAGA, I. Cem anos de descobertas em cosmologia e novos desafios para o século XXI. Revista Brasileira de Ensino de Física, v. 27, n. 1, p. 157-173, mar. 2005.

WEINSTEIN, G. George Gamow and Albert Einstein: Did Einstein say the cosmological constant was the "biggest blunder" he ever made in his life? ArXiv:1310.1033 [Physics.histph], 2013.

ZANETIC, J. Física também é cultura. 1989. Tese de Doutorado. Faculdade de Educação, USP, São Paulo. 